\title{
"Pasar las cosas por el cuerpo siempre es distinto a ponerlo en palabras ¿no?": educación en salud, interculturalidad y teatro del oprimido
}

\author{
"Running things through the body is always different from putting that into \\ words, right?": health education, interculturality and the \\ theater of the oppressed
}

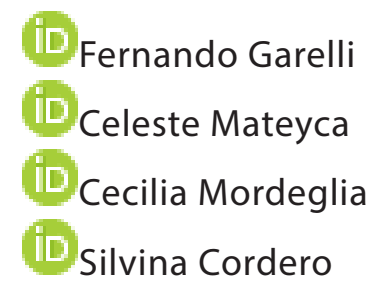

Universidad Nacional de La Plata (UNLP), CONICET, Instituto de Física de Líquidos y Sistemas Biológicos, La Plata, Argentina. Autor correspondiente: comscordero@fahce.unlp.edu.ar

Resumen: Presentamos la sistematización de una experiencia de formación docente en ejercicio desarrollada en 2018-2019, articulando la Educación en Salud y la Interculturalidad crítica extendida, a través del Teatro del Oprimido. A partir del análisis de un caso real, Ixs participantes crearon con sus propios cuerpos imágenes que representaban diferentes situaciones de opresión, para ser analizadas e intervenidas colectivamente. Focalizamos la sistematización en tres ejes: saberes, posicionamientos y reflexiones sobre Salud e Interculturalidad; lo ocurrido al poner el cuerpo y los sentimientos en juego; y al intervenir las imágenes, habilitando la reflexión sobre las posibilidades de transformación de la realidad. La sistematización nos permitió reconocer que el Teatro Imagen implicó un proceso de aprendizaje desarrollado en la propia práctica, que posibilitó explicitar múltiples posturas, incluyendo las políticamente incorrectas. Destacamos la riqueza de dispositivos que habiliten la dimensión de la transformación de la realidad en temáticas como Salud e Interculturalidad.

Palavras-clave: Educación em salud; Interculturalidad; Teatro del oprimido; Formación docente contínua.

Abstract: We present the systematization of an in-service teacher training experience developed in 2018-2019, articulating Health Education and extended critical Interculturality, through the Theater of the Oppressed. Based on a real case, the participants created images with their own bodies that represented different situations of oppression, which were to be analyzed and intervened with collectively. We focus the systematization on three axes: knowledge, positions and reflections on Health and Interculturality; what happened when the body and feelings were put into play; and during the intervention of the images, which allowed for reflection on the possibilities of transforming reality. The systematization led us to recognize that the Image Theater approach implied a learning process developed in the practice itself, which caused multiple positions to be made explicit, including politically incorrect ones. We underline the richness of devices that enable the dimension of the transformation of reality in topics such as Health and Interculturality.

Keywords: Health education; Interculturality; Theater of the oppressed; In-service teacher education.

Recebido em: 11/01/2021

Aprovado em: 31/05/2021 


\section{Introducción}

Presentamos en este trabajo el análisis y la sistematización de una experiencia de formación docente en ejercicio desarrollada en 2018-2019, que articuló Educación en Salud (ES), Teatro e Interculturalidad. Elaboramos este análisis durante el año 2020, atravesado por la pandemia de Covid-19 y por un extenso período de Aislamiento Social Preventivo y Obligatorio en Argentina. Desde nuestro trabajo en el campo de la Educación en Ciencias Naturales, Ambiental y en Salud (ECNAS) (CORDERO et al., 2011), entendemos que esta pandemia, que aún estamos viviendo, es una expresión más de una crisis socio-ambiental que comenzó a ser anunciada en los años '70 del siglo pasado (DUMRAUF; CORDERO; MENGASCINI, 2016) y que es también un síntoma de esta época que muchxs ${ }^{1}$ ya denominan Capitaloceno (MACHADO ARÁOZ, 2020).

¿Qué hacer desde la ES ante esta encrucijada? Las respuestas habituales, elaboradas desde la Educación para la Salud dominante, normativas, moralistas e individualizantes, sólo refuerzan y son parte del Modelo Médico Hegemónico $(\mathrm{MMH})$ que caracterizó Menéndez (2005). Sin embargo, quienes sostenemos una ES democrática y participativa (FAINSOD; BUSCA, 2016), no resignamos la posibilidad de organizarnos, de seguir pensando en conjunto, entre docentes, investigadorxs y organizaciones sociales, aprovechando o elaborando los medios para superar los distanciamientos del momento con las herramientas virtuales o las medidas de cuidado necesarias. Creemos que solo así podemos continuar apostando al pensamiento crítico, la producción de alternativas solidarias, a la autonomía y a la transformación de las condiciones sociales en las que nos subsume el modelo civilizatorio actual.

Es en este contexto de profunda crisis civilizatoria donde el análisis y la sistematización de nuestras experiencias en ES, sustentadas en ese paradigma democrático y orientadas hacia un horizonte emancipador, adquieren sentidos vivificantes e inspiradores. ¿Cómo se hace realmente para que las personas piensen que hay posibilidades de otra cosa? dijo una de las entrevistadas participantes en la experiencia que sistematizamos en este artículo. Nos proponemos reflexionar con ella y explorar cómo el Teatro Imagen, una de las formas del Teatro del Oprimido (TO) (BOAL, 2001), es/ puede ser un medio para entender y vislumbrar las posibilidades de transformación de lo dado, de las opresiones naturalizadas, en el cruce entre las perspectivas de Salud e Interculturalidad que escogimos.

\section{Educación, teatro, interculturalidad y salud}

La propuesta político-pedagógico-didáctica puesta en juego en la experiencia que abordamos en este trabajo se nutre de diferentes perspectivas. Desde lo educativo, nos enmarcamos en la larga tradición de la Educación Popular (EP) Latinoamericana. A partir de reconocer y destacar la dimensión política de la educación, la EP considera al campo educativo como un espacio de lucha de sentidos. En esta lucha, orienta la práctica pedagógica hacia un proyecto colectivo de transformación social que disputa y construye poder (TORRES CARRILLO, 2014) y que, en dicho camino, busca afianzar nuestra autonomía. Si bien no es un movimiento homogéneo, coincidimos

'Utilizamos la letra x para hacer referencia a un amplio universo de expresiones de género que rebasa la bicategorización de 'hombres' y 'mujeres'. 
con Torres Carrillo (2014) y tomamos como propios los que entendemos son los pilares de la EP: el diálogo de saberes, la mirada crítica de la realidad y la perspectiva transformadora/emancipatoria de la educación. Desde el punto de vista de las estrategias, decidimos utilizar el Taller, reconocido como modalidad pedagógica privilegiada en la $E P$, que puede enmarcar diversos dispositivos, poniendo en juego un espacio dialógico a través del trabajo grupal (RÉDUA; KATO, 2020) partiendo de la noción de diálogo como experiencia transformadora, que incluye tanto la historización como el vínculo con el contexto.

Otro de los marcos centrales para el presente trabajo es el TO, una forma teatral eminentemente política y participativa desarrollada por Augusto Boal, con inspiración en la EP y la dramaturgia de Bertolt Brecht. El TO se propone transformar los roles y las relaciones entre personas en la escena teatral, convirtiendo a Ixs espectadorxs en protagonistas de la acción (rompiendo la dicotomía entre espectadorxs y actorxs para convertirnos en espectactorxs) (BOAL, 2001). Esta propuesta cambia la experiencia teatral para configurarla como un espacio colectivo de preparación para actuar en la realidad con una perspectiva de liberación de las opresiones. Es decir que "[...] no se trata sólo de reflexionar sobre el pasado, sino también de preparar el futuro, esto es, se deben transformar todas las situaciones vividas en el espacio escénico en un ensayo para la transformación de la realidad" (PARO; SILVA, 2018, p. 472, traducción nuestra). Dentro del abanico de posibilidades del TO (el Teatro Foro, el Teatro Imagen, el Teatro Invisible, el Teatro Periodístico, el Arcoíris del Deseo, el Teatro Legislativo y las acciones directas) abordamos el dispositivo del Teatro Imagen. Este dispositivo propone representar situaciones problemáticas o de opresión con los cuerpos en forma estática, sin utilizar palabras, para luego abrir un foro de debate con el objetivo de intervenir las imágenes, buscando desarticular las situaciones de opresión identificadas. Según Paro y Silva (2018) tiene como objetivo ampliar la visión en la cual significantes y significados son indisociables, superar las restricciones del lenguaje simbólico de las palabras, en el que las realidades concretas y sensibles son disociadas. A nuestro criterio, el trabajo con el cuerpo (y los sentimientos) en el marco de una experiencia formativa configura, a su vez, un abordaje superador del binarismo moderno mente-cuerpo y de la separación sujeto-objeto (DUMRAUF et al., 2019).

En el ámbito del debate sobre la Interculturalidad en educación existe una diversidad de posturas que van desde la naturalización y búsqueda de armonía en las relaciones culturales a partir de una matriz hegemónica y dominante, hasta la denuncia del carácter político, social y conflictivo de estas relaciones, por concebir a la cultura como una arena de lucha ideológica. En nuestro caso, para reflexionar acerca de la relación de la Salud y la Interculturalidad optamos por la Interculturalidad crítica extendida como perspectiva política y pedagógica (DÍAZ; RODRÍGUEZ DE ANCA, 2014; DIEZ, 2013). Partir de esta perspectiva implica: visibilizarla como una propuesta dirigida a toda la sociedad y no a grupos específicos; comprender la identidad de forma procesual, que se transforma, y que utiliza múltiples referencias a la hora de construirse, no sólo vinculadas a cuestiones étnico-nacionales, sino también de género, edad, clase social o diversidad sexual (entre otras); cuestionar las estructuras y lógicas escolares que producen desigualdades, amparadas y legitimadas por una forma esencialista de entender la diversidad; reconocer los saberes de Ixs estudiantes y la búsqueda de diálogos con los que se enseñan en la escuela. Estos supuestos exigen 
tanto el rechazo al tratamiento folklorista y cosificado de saberes de Ixs estudiantes, como la deconstrucción de la universalidad y neutralidad de los conocimientos escolares (CUCALÓN; CORDERO; DUMRAUF, 2017). Tal tarea, en nuestro caso, se refiere especialmente a los conocimientos abordados en la ES.

Para conceptualizar a la Salud nos nutrimos de los aportes de la Epidemiología Crítica, entendiéndola, entonces, como un campo complejo, polisémico, histórico y territorial. Este se encuentra atravesado e inmerso en una trama dialéctica de determinaciones socio-históricas, procesos en los que interactúan los estilos de vida personales y los modos de vida de los grupos socio-culturales, en una sociedad regida por determinados modelos político-económicos (BREILH, 2013), entretejiéndose lo biológico y médico con lo político y económico, con lo cultural y también con lo ambiental. A su vez, se trata de un campo de intervención, con diferentes modelos en pugna, donde la propia propuesta de la Epidemiología Crítica es la de construir desde una intencionalidad contrahegemónica de salud colectiva opuesta al vigente $\mathrm{MMH}$. De acuerdo con Menéndez (2005) los rasgos centrales del MMH son el biologicismo, el autoritarismo y la consecuente heteronomización de la población (DUMRAUF; GARELLI, 2020) que, prevalentes en la definición de decisiones a tomar y acciones a realizar, desconfiguran o debilitan las alternativas que apuesten a conocimientos y decisiones construidas colectivamente.

A modo de síntesis de lo anterior, a través de nuestra práctica como formadorxs de docentes y profesionales del campo de la ES (CORDERO et al., 2016; DUMRAUF; CORDERO; MENGASCINI, 2016; GARELLI et al., 2017), fuimos construyendo un abordaje multidimensional, intercultural y crítico de la Salud. Sus principios de acción se centran en: (a) complejizar la mirada que habitualmente sólo considera lo biomédico para plantear una perspectiva multidimensional; (b) considerar las problemáticas de salud a abordar de manera colectiva, trascendiendo lo individual; (c) indagar la realidad local, territorial e históricamente; (d) promover la participación activa de Ixs estudiantes, profesionales, vecinxs, y docentes involucradxs en cada contexto; (e) promover el diálogo de saberes; (f) promover la acción colectiva transformadora (CORDERO; GARELLI; CUCALÓN, 2019).

\section{Marco metodológico}

Acudimos a la sistematización de experiencias, desde nuestro lugar de protagonistas formadorxs de docentes e investigadorxs en ECNAS, con las intenciones de penetrar en la trama compleja de la experiencia y recrear los saberes allí construidos, a través de un ejercicio interpretativo de teorización y de apropiación consciente de lo vivido. La sistematización de experiencias consiste en la interpretación crítica que se realiza a partir de un trabajo complejo de ordenamiento y reconstrucción minuciosa de lo acontecido en una experiencia, que incluye la descripción, el análisis y la reflexión sobre lo ocurrido. Ello exige un camino que permita tomar distancia de la experiencia vivida, reconstruir el recorrido de los diferentes acontecimientos, dejando que'hablen' por sí mismos, para luego formular preguntas críticas que posibiliten analizarlos en profundidad, reflexionar y construir conocimiento (JARA H., 2018). 
El proceso de sistematización nos implicó a Ixs autorxs una reconstrucción histórica de la experiencia para la que tomamos como fuentes de información la planificación y los registros en audio, video y fotográficos de las implementaciones del Taller, nuestros intercambios como grupo coordinador tanto vía correo electrónico como WhatsApp, y las memorias y audios del balance docente que realizamos luego de cada implementación. A su vez, realizamos entrevistas a ocho participantes de los Talleres, construyendo un guión semi-estructurado a partir de los ejes de sistematización, incorporando también sus voces a la indagación. Todo este proceso se realizó en un constante 'ir y venir' entre las distintas etapas de la sistematización y los marcos teóricos, reformulando en varias ocasiones la reconstrucción, los ejes y el análisis. Nuestra intencionalidad fue mejorar la experiencia, ver qué aprendizajes surgen de estas prácticas y fundamentar el uso del cuerpo por medio del Teatro Imagen para abordar estos temas. Específicamente focalizamos en tres ejes de sistematización: (1) Qué saberes, posicionamientos y reflexiones circularon sobre Salud e Interculturalidad a través de este dispositivo de formación; (2) Qué ocurrió al poner el cuerpo y los sentimientos en juego en estas situaciones formativas; (3) Qué ocurrió al intervenir las escenas, habilitando la reflexión sobre las posibilidades de transformación de la realidad.

\section{Contexto y estructura de los talleres}

La experiencia educativa que sistematizamos en este trabajo surgió en el marco de una propuesta de formación docente continua más amplia realizada durante los años 2018 y 2019, enmarcada en los Proyectos de Extensión Promoción de la Salud Comunitaria y Formación Docente (Facultad de Humanidades y Ciencias de la Educación, Universidad Nacional de La Plata, 2018-2019) y Voluntariado Universitario Tejiendo saberes: Puentes entre escuela y universidad (Facultad de Ciencias Naturales y Museo, Universidad Nacional de La Plata, 2018-2019). El proceso de formación constó de cinco encuentros-talleres, en los que se abordaron los siguientes temas: (1) Finalidades y enfoques en la Educación Sexual Integral (ESI), Ambiental y en Salud; (2) Géneros y patriarcado, desde el punto de vista de la ESI; (3) ES e Interculturalidad; (4) Educación Ambiental, Mapeo Colectivo y Conflictos Ambientales; y (5) Propuestas colectivas de transformación de prácticas. Todo el proceso formativo fue diagramado y coordinado por un equipo interdisciplinario de personas con diferentes recorridos académicos e institucionales (investigadorxs, docentes universitarixs y de escuelas primarias y secundarias, estudiantes universitarixs). Lxs participantes fueron docentes de escuelas públicas de diferentes áreas curriculares y niveles educativos.

El Taller de ES e Interculturalidad se implementó en cuatro oportunidades en esos dos años: como parte de una etapa de formación interna del equipo coordinador y de ajuste de la planificación (2018), con dos grupos de docentes diferentes en el marco del proceso formativo (2018) y con un grupo de estudiantes de Ciencias de la Educación, docentes en ejercicio y promotoras de salud (2019). En este trabajo focalizamos en las implementaciones realizadas con docentes (que Ilamaremos Taller 2018 A, Taller 2018 B y Taller 2019), que fueron las más detalladamente documentadas y que siguieron la misma secuencia didáctica. 


\section{Secuencia didáctica del taller analizado}

1. Indagación de ideas sobre salud: se pidió a cada participante que respondiera por escrito en un papel: ¿qué me hace bien a mí y a mi entorno? El equipo coordinador sistematizó las respuestas.

2. Presentación de problemática: proyección de fragmentos seleccionados de la película Gerónima.

3. Análisis, reflexión y puesta del cuerpo en colectivo a partir de la problemática presentada:

a. Formación de subgrupos a través de una técnica lúdica.

b. Lectura de la sinopsis de la película y reflexión en torno a:

¿Cuál es el problema o cuáles son los problemas?

¿Qué sujetos participan? ¿Qué hacen?

¿Cuáles son sus argumentos/fundamentos?

¿Qué considera saludable cada unx de Ixs sujetos?

c. Lectura de un fragmento de texto sobre interculturalidad extendida (DÍAZ; RODRÍGUEZ DE ANCA, 2014) y reflexión grupal sobre: ¿Qué nos aporta la idea de interculturalidad extendida para pensar la historia de Gerónima?

d. Construcción de una imagen formada con los cuerpos estáticos, sin diálogos, a partir de las conclusiones de la discusión grupal.

4. Teatro del oprimido y Teatro-imagen: Breve explicación de la historia del Teatro del oprimido y del dispositivo del Teatro-imagen. Presentación de las imágenes elaboradas por cada grupo y análisis en cuatro etapas:

a. Instante de ver: análisis desde el punto de vista de quienes miran la imagen.

b. Las emociones en escena: explicitación desde el punto de vista de Ixs personajes actuantes.

c. La perspectiva del grupo diseñador: explicación desde quienes construyeron la imagen.

d. Ensayos para la transformación: a partir de una imagen seleccionada por la coordinación, preguntamos: ¿Cómo podríamos modificar esta situación? Quienes observan realizan cambios sobre las personas actuantes. Se reflexiona sobre los aportes y sobre la modificación de la situación y se evalúa si la situación de opresión se quiebra o no.

5. Conceptualización: reflexión colectiva sobre las imágenes, sus modificaciones y los saberes que circularon. Nos preguntamos: ¿qué entendemos cuando hablamos de interculturalidad crítica extendida en Educación en Salud? Presentación de la sistematización de ideas de salud reconstruidas con base en las respuestas individuales iniciales sobre: qué me hace bien a mí y a mi entorno. Exposición docente de las dimensiones identificadas en la reconstrucción y características de la salud emergentes. Reflexión colectiva acerca de cuáles de estas dimensiones son abordadas en la escuela.

6. Elaboración de propuestas grupales extra-clase: respuesta a las siguientes preguntas en grupos: ¿Qué problemáticas de salud significativas para la población forman parte del curriculum nulo y podrían abordarse en la escuela? ¿Cuál es la problemática que nos planteamos trabajar en la propuesta didáctica que planificamos? ¿Por qué es una problemática?

Para reflexionar acerca del vínculo entre la Salud y la Interculturalidad, en este Taller decidimos utilizar la problemática presentada en la película Gerónima (1986), que representa la historia de vida compleja e injusta de una mujer mapuche en el año 1976 en la Patagonia argentina. Gerónima vivía con sus cuatro hijxs en la estepa patagónica hasta que intervinieron funcionarios estatales que Ixs Ilevaron a un hospital, pues consideraron que vivían en condiciones insalubres. Sin embargo, el doloroso paso por el hospital, en el que Gerónima y sus hijxs fueron separadxs en salas diferentes y sometidxs a las lógicas hospitalarias, terminó implicando que tres de Ixs niñxs contrajeran coqueluche y murieran, en tanto Gerónima entró en estado de depresión y enloqueció. Una frase de Gerónima, dicha en el hospital, sintetiza este drama: "No quiero que me den una mano, quiero que me saquen las manos de encima". El trabajo desde el Teatro Imagen acerca de Salud e Interculturalidad se basó en esta historia. 


\section{Reconstrucción de las experiencias vividas: algunas escena}

Presentamos a continuación algunas escenas reconstruidas principalmente a partir del visionado de las videofilmaciones de los Talleres realizado por Ixs autores de este trabajo. Para ello, nos centramos en el momento del TO, donde los grupos armados en cada Taller presentaron imágenes elaboradas con sus cuerpos basadas en su análisis de la película Gerónima. En cada caso, Ixs coordinadorxs seleccionamos una de estas imágenes para intervenirla colectivamente y profundizar en su análisis con el grupo cursante.

Como indica Palumbo (2020), reconstruir una escena es un gesto interpretativo que permite, por un lado, narrar lo ocurrido durante un Taller, expresando de un modo locuaz un relato de una experiencia para luego, cargado de significado, analizarlo, problematizarlo.

La potencialidad del uso de escenas radica en habilitar interpretaciones complejas que recojan los múltiples sentidos - a veces contradictorios puestos en juego en una misma trama. Adicionalmente, las escenas conducen a la articulación de teorías y prácticas a partir de una mutua interpelación, generando modos de análisis que anudan materialidad y pensamiento (PALUMBO, 2020, p. 283).

\section{Escena 1 (taller 2018 A): los cuerpos}

Un grupo de participantes se ofreció a pasar y empezar. A pesar de esto, no se las notaba cómodas, una de las integrantes del grupo preguntó: "¿Es un pick [con gesto de sacar una foto] y listo, no?". Pero el coordinador les pidió que esperaran un poco, que teníamos que analizar esa imagen entre todxs. Sus cuerpos, y los de quienes observábamos, manifestaban tensión, cierta timidez y nerviosismo. Había una rigidez $y$, de hecho, las participaciones para describir la imagen fueron limitadas, tuvimos que ganar protagonismo y orientación quienes coordinábamos. En esa imagen (figura 1A) identificamos colectivamente relaciones de opresión. Observamos a "una mujer a la que no le permiten ver ni escuchar ni hablar". Parecía que era el Estado, Ixs vecinxs, el cuerpo médico y todxs Ixs que intervinieron quienes le tapaban los ojos, los oídos y la boca a Gerónima y a su familia. La posición era difícil de mantener, los cuerpos se cansaban. Pedimos a las actrices que se pusieran en una postura cómoda, que pudieran sostener. Gerónima, que estaba agachada, se irguió, se rearmó la imagen. Describimos como "indiferentes" a ese grupo de personas o entes que estaban sometiendo a la mujer. Hablamos de "sumisión", "dolor", "padecimiento". Se terminó el análisis y entre risas, malestares de rodillas flexionadas por tiempo prolongado y nervios, las protagonistas explicaron que logramos interpretar lo que ellas querían expresar. Y agregaron que esa mujer agachada y sometida estaba representando a muchas personas que atraviesan esa situación: "no la dejamos ser, expresar su cultura, sino que nosotros estamos avasallando a través de no permitirle hablar, no permitirle escuchar, no permitirle ver, pretendemos que vea lo que nosotros queremos y no su cultura".

El segundo grupo también se ofreció a presentar su imagen y, a pesar del contenido dramático que mostraron, surgieron risas tanto de quienes actuaban como de quienes analizaban. La imagen (figura 1B) mostraba a un hombre parado sobre una silla, en un gesto de comodidad, con una mano en un bolsillo y la otra forcejeando con una mujer sobre un objeto (un muñeco) que - como aclararon luego - simbolizaba 
a unx niñx. Al lado de ella, estaba de pie otra mujer, embarazada, con sus manos sobre el vientre. Un cuarto personaje era otra mujer acostada en el suelo, entre sus compañerxs, con los brazos cruzados sobre el pecho y los ojos cerrados. Fue como si la tensión durante la primera presentación hubiera comenzado a liberarse en ésta en actitudes más atentas y de involucramiento en la experiencia - más evidentemente desde el gesto y la disposición corporal del grupo que ya había actuado -, llevando a algunxs a tentarse y reír, pero, al mismo tiempo, permitiendo mayor profundidad en las interpretaciones. También la actuación, sobre todo del participante varón, mostró matices gestuales y compenetración con el personaje. La coordinación perdió protagonismo, aparecieron diversas interpretaciones de lo observado, más ricas y complejas y fueron cuestionadas entre Ixs propixs observadorxs. El análisis colectivo llevó a pensar la imagen como una crónica vinculada a la violencia de género, la historia de vida de una mujer violentada por un sujeto que se erige en una clara posición de jerarquía y superioridad. Con la explicitación de los sentidos que el grupo que actuó quería mostrar en la imagen apareció la Interculturalidad extendida, dando cuenta del cruce de opresiones del Estado y el Patriarcado, de género y etnia.

El tercer grupo tuvo más dificultades para mostrar la imagen pensada: "la repensamos, pero no nos sale" dijo una de las integrantes. Decidir hacia qué frente presentarla, cuándo la consideraban lista, y escuchar las interpretaciones que iban surgiendo, Ixs fue llevando a armar y desarmar varias veces la puesta, intensificando algunos gestos. La imagen representada (figura 1C) exigía mayor contacto corporal, en una suerte de entrelazamiento de Ixs participantes: una de ellas abrazaba a otra, apoyándose mutuamente las cabezas sobre los hombros, mientras una mujer y un varón con un brazo enlazado, tironeaba él de una de las participantes y ella mantenía, sin tocarla, la mano por encima de su cabeza. Comenzamos a girar alrededor de ellxs, nos acercamos y alejamos, desenredamos esos brazos entrelazados, esos cuerpos abrazados para entender qué nos estaban diciendo: esa mujer estaba sufriendo, siendo oprimida, esa otra estaba conteniéndola, un hombre parecía protegerla, impidiendo que la ayudaran o tironeando a la mujer oprimida. La que tenía la mano por encima de la cabeza de su compañera ¿la quería agarrar de los pelos? ¿la estaba protegiendo? ¿le estaba imponiendo alguna ideología? ¿no la tocaba porque le daba asco? En este ambiente distendido y activo, algunas coordinadoras nos involucramos fuertemente en la interpretación, momentáneamente cambiando de rol. Interpretar la imagen fue dificultoso, pero quienes observábamos pudimos identificar, tal como el grupo quería expresar, dos formas diferentes de ejercer la violencia, una de carácter físico y otra de tipo ideológico. A éstas, Ixs integrantes del grupo las mencionaron como las dos caras del paternalismo, una que supuestamente tiene la intención de proteger, y otra que avasallaba sin tener en cuenta las necesidades y deseos de las personas. El grupo además destacó el vínculo de protección y amor establecido por Gerónima hacia sus hijxs. 
Figura 1 - Imágenes descriptas en las escenas

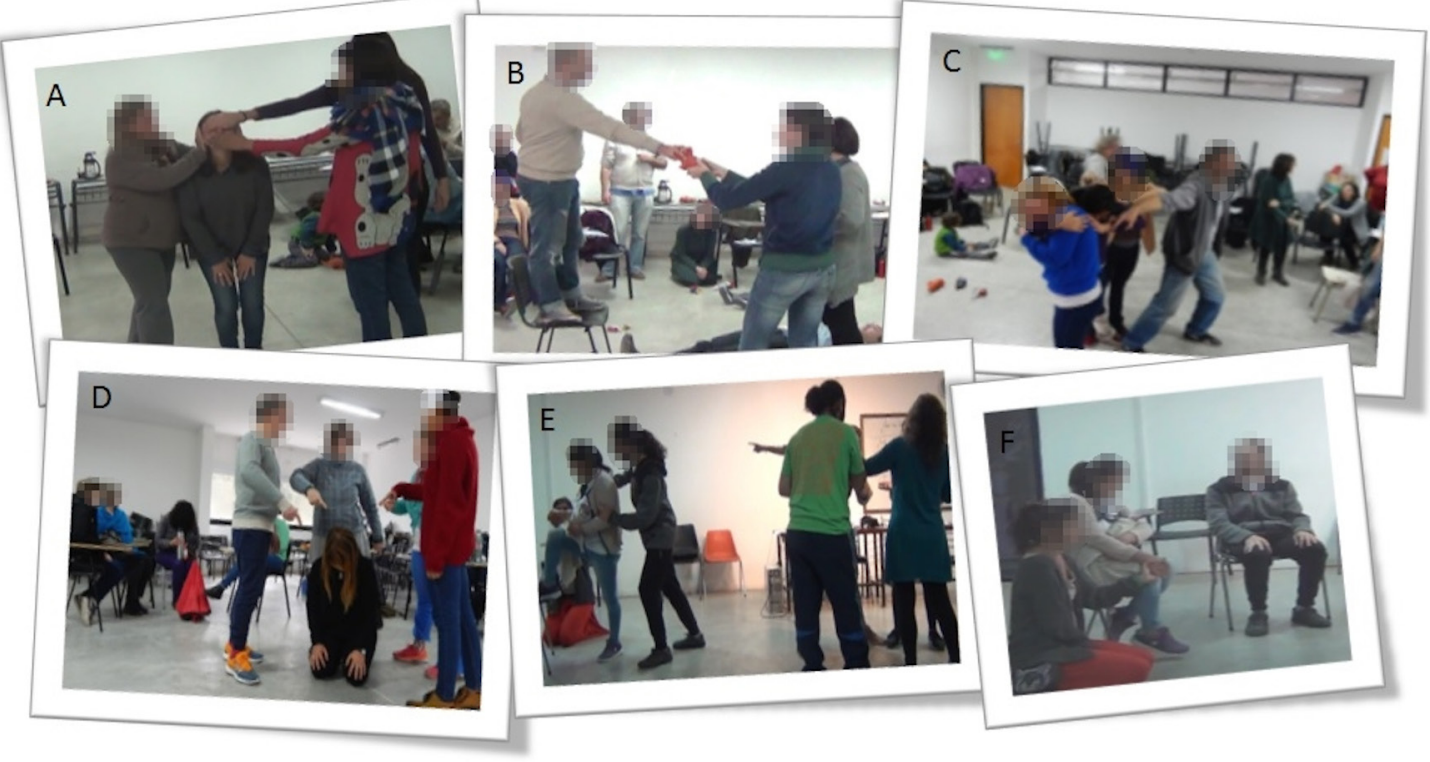

Fuente: elaboración de los autores.

\section{Escena 2 (taller 2018 B): las interpretaciones}

Bajo la dirección de una de las integrantes del grupo, que indicaba la ubicación y las expresiones de cada personaje, Ixs nueve participantes en la imagen se colocaron en dos sub-escenarios (figura 1D). En uno, había una mujer arrodillada y cuatro personas de pie a su alrededor señalándola. En el otro, un semicírculo de cuatro mujeres sentadas rodeando a un paraguas rojo, una de ellas con la cara tapada por su propio pelo largo y negro sostenía un termo y un mate. "Ya están? Quietas. A ver qué vemos". Nadie se movió para observar con detalle las sutilezas de la escena, desde sus lugares comenzaron a interpretar. "Estigmatización", "silencio" y "sumisión" fueron las primeras palabras que surgieron. Expresaron que en un subescenario Gerónima estaba siendo señalada, estigmatizada por el cuerpo médico, mientras que en el otro no. Parecían dos "situaciones paralelas" comentó una participante. Pero luego, el grupo que observaba cambió de parecer. Comenzó a tomar relevancia la idea que planteaba que los dos sub-escenarios representaban situaciones similares de opresión: en uno Gerónima era señalada y estigmatizada, y en otro Gerónima era representada con un paraguas, es decir, era un objeto, se la cosificaba. Esta idea incomodó a Ixs integrantes del grupo, Ixs hizo abandonar sus personajes, comenzaron a reírse, a hablar entre ellxs. "¿Se puede modificar algo de la imagen allá para que se entienda un poquito mejor?" irrumpió quien asignó los roles al inicio. Saliendo de su lugar, modificó los gestos y las expresiones del grupo alrededor del paraguas. Quienes interpretábamos la escena no entendimos los cambios. "¿Es el riesgo del Teatro Imagen!" Planteó una coordinadora. Cuando finalizó el momento de la interpretación, integrantes del grupo agarraron el paraguas rojo y dijeron: "Esto era un fuego". Gerónima era la mujer con el cabello en la cara, con el termo y mate en la mano. Su intención había sido mostrar dos escenarios: uno de opresión, en el que Gerónima era señalada e inferiorizada y otro de diálogo y horizontalidad, en el que Gerónima tomaba mate con diferentes actores sociales. Al final, apareció una reflexión interesante por parte de uno de Ixs que observábamos la escena: "los que cristalizamos a Gerónima fuimos nosotros". 


\section{Escena 3 (taller 2019): las transformaciones}

En este Taller elegimos la imagen del grupo 2 para pensar colectivamente cómo transformarla (figura 1E). Esta imagen contenía varios personajes, organizadxs en dos grupos: en uno, una mujer, parada con un pie sobre una silla, sostenía un atado de ropas con una de sus manos, que simulaba ser unx bebé. Mientras un varón la empujaba hacia adelante, con su otra mano ella tomaba la de otra mujer, arrodillada en el piso. A cierta distancia había una ronda formada por otras tres mujeres y un varón: una de ellas gesticulaba, como gritando, y señalaba hacia el primer grupo de personas; otra levantaba los brazos como diciendo "no sé"; mientras que el varón se tomaba el mentón y la otra mujer levantaba su cabeza, como si se preguntaran algo.

La imagen retomó el momento de la película en que Gerónima subía al camión militar para ser llevada por un gendarme al hospital, sosteniendo en brazos a su bebé y de la mano a otra hija. Las otras personas representaban las voces de "lo que se dice", señalaban lo que pasaba, pero sin estar muy atentxs, atadxs a prejuicios y estereotipos, interviniendo "sobre algo que no conocían, desde otro lugar".

Había que modificar esa situación opresiva desde una perspectiva emancipadora. Y "factible" - aclaramos Ixs coordinadorxs. Pero antes les preguntamos cómo se sentían a Ixs personajes. Lo cual mostró sus tensiones: "había que hacer algo", dijo una de las mujeres, quizás la enfermera. Gerónima habló de su tristeza, por dejar su casa y su perro solo, mientras que su hija expresó miedo. El gendarme dijo: "¿Yo? Ya me quiero ir. Tuve que venir al medio de la nada a buscar a esta gente que vive mal, así que ya quiero volver y terminar con este problema".

Las propuestas iniciales de transformación de quienes observábamos apuntaron sólo a cambiar las posiciones del primer grupo de personas, sentando a Gerónima y al gendarme, una al lado del otro, en una situación de diálogo que podría haber ocurrido en la misma casa de Gerónima (figura 1F). "¿Esto les parece posible que haya pasado? Algo factible ¿o no?" - cuestionamos desde la coordinación - "¿Les parece posible que el gendarme se transforme en alguien que dialoga?". Varixs rieron, negando esa posibilidad. "Sería fantástico que el militar de repente se ponga a dialogar, pero ¿cómo pasó eso?" agregamos. La aclaración de que esta propuesta sería un caso de 'solución mágica', según el TO, es decir "cuando el opresor deja de ser opresor y no sabemos por qué ni cómo", nos decidió a retrotraer la imagen a la puesta original. "¿Cómo eliminamos al opresor?" preguntó alguien, poniendo en palabras la dificultad que sentíamos todxs.

La situación era compleja y los sentimientos expresados por quienes actuaban implicaron una rápida sucesión de propuestas de alteración. Desde colocar al varón del segundo grupo en posición de agarrar al gendarme, cambiar los gestos de las mujeres que gritaban o preguntaban, acercar a la mujer 'médico' a ese sector de la puesta y sentar a Gerónima y su hija frente a ella; hasta sumar a todo el segundo grupo del comienzo interpuesto entre el gendarme y Gerónima, enfrentán dose a su voluntad. Ante esta solución, "algo colectivo que está haciendo una barrera, resistiéndose contra el gendarme", que "evita que el Estado opresor llegue a ellxs" - sostuvo una observadora -, sorprendió el sentimiento expresado por Gerónima, mirando a las mujeres que, supuestamente, la defendían: "Triste, porque ella me da la espalda". 
La siguiente alternativa - aparentemente final - pretendió atender al pedido de Gerónima: una participante hizo que la enfermera y 'el pueblo' sacaran al gendarme de escena, y ubicó a Ixs otrxs dos personajes junto a Gerónima y su hija, sentadas en ronda. Aún en esa situación de supuesta cercanía y diálogo, con personas amables como dijo la hija de Gerónima - quien actuaba de médico expresó su incomodidad, su dificultad para saber cómo actuar o qué decir en ese contexto. Ya expulsado de la escena, quien antes hacía de gendarme, propuso una modificación más, haciendo que la médica tomara la mano de la niña y la mirara a los ojos, una conexión que generó en ellas confianza y la posibilidad de otro tipo de vínculo. Pero Gerónima siguió preocupada: una desconocida estaba tocando a su hija.

\section{Aprendiendo de nuestra experiencia}

El proceso de sistematización, con sus vaivenes, sus bifurcaciones y su apuesta constante al diálogo crítico, nos resultó muy enriquecedor a Ixs autorxs de este artículo. También nos exigió muchas horas de trabajo colectivo, aún a distancia y en contexto de pandemia. Podríamos dividir los aprendizajes que obtuvimos entre aquellos que nos sirven para transformar nuestra experiencia en futuros procesos de formación docente y aquellos que entendemos pueden aportar a otrxs a partir de la reflexión sobre la práctica en este cruce entre Salud, Educación, Interculturalidad y Teatro del Oprimido. En los próximos apartados, intentamos articular análisis y reflexiones surgidas durante el proceso de sistematización, con elementos que buscamos mostrar en las escenas reconstruidas y recuerdos e interpretaciones de la experiencia relevados a través de las entrevistas a participantes.

\section{Aprendizajes para la planificación y la coordinación}

Durante el análisis de los videos y las posteriores reflexiones colectivas, nos surgieron muchas propuestas de mejoramiento del Taller, sobre todo pensando en nuestras estrategias de coordinación y planificación para el momento del Teatro Imagen. Si bien suele ser parte de nuestro enfoque y manera de coordinar, encontramos que hubiera sido posible profundizar aún más la circulación de la palabra, especialmente en los casos en que algunas personas tendían a acaparar la atención. A su vez, considerando lo movilizador del trabajo con el cuerpo y del aprendizaje vivenciando la experiencia, creemos que sería importante hacer el cierre del Taller en otro encuentro. También reflexionamos que sería enriquecedor romper aún más las diferencias entre espectadores y actores en las escenas, a partir de pautas como: preguntar sensaciones a quienes están analizando/interpretando la escena, habilitar diálogos entre quienes interpretan y quienes ponen el cuerpo en la imagen y considerar la posibilidad de incluir en la planificación que quienes están en la imagen puedan realizar modificaciones. Las personas entrevistadas también hicieron aportes para futuras implementaciones de la propuesta: pensar un aumento de la duración del Taller agregando un segundo encuentro; incluir una instancia escrita de conceptualización final; generar una producción para poder compartir después en los territorios; planificar un momento de evaluación colectiva del Taller. 


\section{El trabajo en torno a salud e interculturalidad a través del teatro imagen}

Todas las implementaciones del taller y las imágenes construidas fueron atravesadas por dos reflexiones centrales: el cuestionamiento al poder del $\mathrm{MMH}$ y la estigmatización y las relaciones de opresión socio-culturales, fundamentalmente desde el racismo y el patriarcado. Vale decir que la estrategia permitió visualizar aspectos como la vinculación de la Salud con las relaciones de poder, es decir la dimensión política de la Salud y la dimensión socio-cultural, al mostrarse la imposición de una concepción de Salud biomédica sobre otra. Y respecto de la Interculturalidad, además de las situaciones de desigualdad generadas desde el punto de vista étnico, las debidas a las relaciones desiguales de género y de rol social.

A través del análisis de la historia de Gerónima y las distintas imágenes presentadas se discutieron conceptos como diversidad cultural, intercambio, silenciamientos, relaciones de poder, relaciones de desigualdad, salud-insalubridad, $\mathrm{ES}, \mathrm{MMH}$, patriarcado, colonialismo cultural y etnocentrismo.

Como se plantea en la secuencia didáctica del talle analizado, a fin de ingresar a la discusión de las experiencias e ideas personales sobre la Salud, al inicio del encuentro se había realizado un trabajo individual de reflexión y escritura acerca de "qué me hace bien a mí y a mi entorno". La interpretación de las expresiones utilizadas por Ixs cursantes permitió reconocer asociaciones de la Salud con la dimensión psicológica personal e interpersonal (hubo expresiones desde"estar al aire libre", hasta "relaciones saludables, sin violencia, con respeto, con diálogo"); con el trabajo ("digno"); con una dimensión ambiental ("ambiente sano"); y con acciones fundamentalmente individuales.

Estas ideas fueron retomadas en el momento de conceptualización posterior al trabajo desde el Teatro Imagen, en el que en cada implementación entretejimos lo reflexionado por los grupos, pretendiendo aportar una sistematización de las concepciones y dimensiones de la Salud abordadas en las producciones individuales y en las imágenes grupales. Entre otros aspectos, se definió a la Salud como un proceso que incluye salud-enfermedad-atención, multidimensional, dinámico, histórico, conflictivo y colectivo. En alguna implementación también se diferenció esta idea de las definiciones habituales de Salud que aparecen en los libros escolares como "estado de completo bienestar", o "estado de equilibrio bio-psico-social" de la Organización Mundial de la Salud, contraponiendo el carácter multidimensional que, a través del trabajo realizado, adquirió el concepto. Además, se puso en tensión la práctica educativa usual que sólo aborda la dimensión biológica del concepto. También se teorizó y reflexionó acerca de las visiones circulantes de la cultura y la diversidad, en general esencialistas, folklorizantes y estereotipantes. Se vinculó una noción más dinámica de la cultura con la desigualdad y la articulación de opresiones a través de sistemas como el colonialismo, el patriarcado y el capitalismo. Finalmente, en todas las implementaciones recuperamos la noción de Interculturalidad crítica extendida $y$, revisando otras versiones habituales de la Interculturalidad (DÍAZ; RODRÍGUEZ DE ANCA, 2014), se reflexionó acerca de las manifestaciones y los conflictos generados por la expresión de dichos sistemas de opresión hacia el interior del ámbito y las relaciones escolares. De esta manera, pudimos trabajar estos temas desde la palabra, a través del Teatro Imagen y en una reflexión colectiva posterior en la que volvimos a la palabra. 


\section{Saberes, posicionamientos y reflexiones: la puesta en juego de la diversidad}

Al analizar las tres implementaciones del Taller un aspecto que llamó la atención fue la heterogeneidad de lo ocurrido en el Teatro Imagen. Más allá de que se haya trabajado sobre las mismas temáticas y con el mismo dispositivo, entendemos que los saberes, posicionamientos y reflexiones puestos en juego en las tres experiencias analizadas resultaron diferentes.

Asociamos estos diversos procesos en cada implementación con la heterogeneidad en las trayectorias de Ixs participantes, quienes contaban con distintas formaciones y experiencias de vida. En este sentido, las imágenes y sus modificaciones permitieron mostrar diferentes tipos de conflicto: en el Taller $2018 \mathrm{~A}$ la figura del opresor se transformó específicamente en el patriarcado y, a la hora de intervenir la imagen, la propuesta final de 'matar al patriarcado' y levantar los puños victoriosas no conformó a todas las participantes, evidenciando el carácter conflictivo de las relaciones interculturales en su dimensión de géneros. En el Taller 2018 B, las imágenes construidas por los grupos mostraron las formas del paternalismo asociadas al MMH y la película, pero desde una visión mucho más estereotipada. Aún más, dos de las tres imágenes presentadas ese día - una de ellas recreada en nuestra Escena 2 - mostraban al mismo tiempo la situación de opresión y una posible pero ideal resolución de los conflictos, en dos espacios diferenciados por la distribución de Ixs participantes. En el Taller 2019, la presencia y las intervenciones de las promotoras de salud de un movimiento social, junto a estudiantes y docentes, habilitaron otros saberes, posicionamientos y formas de actuar que no identificamos en los otros dos encuentros. De hecho, se trataba de personas con una historia de vida más cercana a la de la protagonista de la película. Historia de vida que, como puede verse en nuestra Escena 3, hasta último momento hizo que la promotora que encarnaba el personaje de Gerónima siguiera sintiendo miedo o preocupación frente a esas personas que, supuestamente, pretendían ayudarla, pero nunca le preguntaban qué deseaba o pensaba.

Esta heterogeneidad también fue retomada en algunas entrevistas, ya que hubo quien registró la existencia en el grupo cursante de miradas hegemónicas sobre la Salud y la Interculturalidad, y la vinculó a la diversidad de quienes habitan las escuelas y sus formaciones previas. Algunxs recordaban fundamentalmente el proceso del Teatro Imagen y la reflexión generada; otras también destacaron el trabajo en subgrupos, el valor positivo de la pregunta inicial sobre "qué te hace bien a vos y a tu entorno" y quien recordaba en detalle la película. En cuanto a qué se llevaron como aprendizajes del Taller, las personas entrevistadas destacaron: cuestiones vinculadas a la comunicación con Ixs otrxs, que podrían relacionarse con la visión de Interculturalidad planteada (generar ronda de diálogo con mujeres en sus organizaciones; reforzar la importancia de preguntar antes de opinar o proponer acciones; dar a conocer el rol de promotoras; formas de comunicación /participación en la organización); cuestiones conceptuales novedosas, tales como el concepto de Salud, de MMH, de Interculturalidad extendida; y cuestiones metodológicas, como la potencialidad de realizar reflexiones conceptuales a partir de poner el cuerpo, la forma de trabajo horizontal durante el taller y la posibilidad de usar el TO en tanto forma de pensar cómo revertir situaciones de violencia. 
Conceptualizamos esta heterogeneidad como algo propio de los procesos de diálogo en los talleres de EP. En este caso lo entendemos como un diálogo que no sólo incluyó saberes sino también sentires, creencias, sueños, preocupaciones, intereses, dudas, miedos, confianzas y desconfianzas, algo que Merçon et al. (2014) Ilamaron diálogo de vivires. Si bien creemos que estas dimensiones de la experiencia humana están siempre presentes en los procesos educativos, en este caso, a través del dispositivo del Teatro Imagen, se hicieron explícitos al poner el cuerpo y verbalizar los sentimientos, poniéndolos en juego junto con los saberes en el proceso del Taller.

\section{Aprendiendo a jugar: qué ocurrió al poner el cuerpo y los sentimientos y reflexionar sobre ello}

Al recorrer los encuentros a partir de los videos, con el ejercicio de distanciamiento que implica la sistematización, observamos en los grupos un proceso de aprendizaje asociado a poner el cuerpo. Así como hemos registrado en experiencias anteriores de trabajo con el Teatro Imagen, en dos de las implementaciones analizadas en este artículo ocurrieron procesos graduales de ir aprendiendo a jugar un juego nuevo, a poner el cuerpo, a traer los sentimientos a escena, a romper con la vergüenza de una exposición a la que la mayoría no estaba acostumbradx en procesos educativos previos. Una entrevistada expresó que le "resultó al principio como raro el poner el cuerpo y esas dinámicas en la Facultad". Como describimos en la Escena 1, este progresivo adentramiento en la propuesta teatral implicó ir dejando de lado rigideces para empezar a disponibilizar el cuerpo y poder compenetrarse con la experiencia, involucrando diversos posicionamientos sobre Salud e Interculturalidad y el análisis trabajado en subgrupos.

Sólo en una de las implementaciones delTaller no percibimos ese proceso gradual de involucramiento. Si bien la película movilizó muchas reflexiones, y la secuencia de actividades se desarrolló tal como estaba planteada, durante todo el encuentro prevalecieron las individualidades, dominaron algunas voces especialmente y fue muy variable el compromiso al momento de la actuación (Ilegando una participante a negarse a actuar con su grupo) y la interpretación (como se ve en la reconstrucción de la Escena 2, nadie se movía de su sitio al momento de interpretar las escenas, sin apropiarse del espacio del aula). Nuestra lectura de esta implementación fue que la participación desigual y cierta indecisión desde la coordinación para estimular la circulación de la palabra, dificultaron la construcción de grupalidad en este caso, probablemente necesaria para lograr un proceso de involucramiento progresivo y compartido en el juego teatral. Sin embargo, nuestra Escena 2 pretendió mostrar cuán interesante fue el trabajo de interpretación de las imágenes, más allá de sus dificultades. La apertura del lenguaje corporal, que habilita multiplicidad de interpretaciones, permite la expresión, no sólo de quienes actúan, sino también de quienes observan y analizan la imagen. Fue así que en las interpretaciones de la imagen presentada en la Escena 2, sin ser la intención del grupo que actuaba y habiendo circulado otras posibles lecturas de la imagen, se insistió en visualizar la cosificación de Gerónima, aún en situaciones bien diferentes y a pesar de los esfuerzos de explicitación corporal por parte de quienes la habían construido. Como remarcó uno de los observadores, fuimos quienes analizábamos la imagen Ixs que sólo podíamos ver en ella la cristalización-cosificación 
de Gerónima. Rivera Cusicanqui (2014) dice, respecto de la sociología de la imagen, "[...] las culturas visuales, en tanto pueden aportar a la comprensión de lo social, se han desarrollado con una trayectoria propia, que a la vez revela y reactualiza muchos aspectos no conscientes del mundo social" (RIVERA CUSICANQUI, 2014, p. 20). Esta posibilidad de verbalizar una acción o un pensamiento políticamente incorrecto, que develaría valores o aspectos grupales no conscientes, como metaanálisis de su propia práctica interpretativa, fue habilitada por lo lúdico del Teatro Imagen que, a pesar de los obstáculos en el funcionamiento grupal, generó un espacio de cierta confianza y de autocuestionamiento en algunxs participantes.

Más allá de los distintos procesos vivenciados en cada implementación, poner el cuerpo generó sentimientos rememorados por las personas entrevistadas como de vergüenza, incomodidad, timidez, nervios, movilización en muchos casos y, en algunos casos que ya contaban con una trayectoria y experiencia en este tipo de propuestas, gusto y disfrute.

La diversidad de procesos grupales no implicó, a nuestro criterio, que no se hayan producido aprendizajes. Es más, fue recurrente en las entrevistas la asociación entre la experiencia de poner el cuerpo y el aprendizaje. Las personas entrevistadas destacaron como riquezas de la estrategia del Teatro Imagen aspectos muy relevantes y diversos a la hora de pensar cómo potenciar los aprendizajes. En algunos casos señalaron las múltiples ideas que moviliza en un tiempo acotado: "permite construir muchas ideas en poco tiempo"; "te hace pensar más cosas". En otro, identificaron que "habilita otros canales para pensarse", es decir, para reflexionar sobre unx mismx. También lo entendieron como "otro lenguaje, que permite trabajar conceptos difíciles", es decir profundizar en dimensiones conceptuales muchas veces no comprendidas desde lo verbal. Además, al ser una estrategia planteada desde y para lo grupal, "permite trabajar lo colectivo". Y finalmente consideraron que "poner el cuerpo consciente y grupalmente, sacándolo de la cotidianeidad para analizarlo, marca". De esta manera, podríamos decir que, tal como se propone el Teatro Imagen desde lo teórico, Ixs entrevistadxs identificarían en la experiencia una ampliación de sentidos respecto de situaciones formativas en ES en las que se trabaja sólo desde la palabra.

\section{La dimensión de la transformación: qué ocurrió al intervenir las imágenes}

El momento de intervenir y transformar las imágenes probablemente haya sido el más rico a los ojos de nuestro análisis. En esta parte del proceso podríamos decir que confluyeron los diferentes contenidos abordados, así como la perspectiva pedagógica asumida, con los saberes, vivencias y trayectorias de Ixs participantes. Habilitar la dimensión de la transformación es un signo distintivo de la EP, desde donde no se trata de "[...] conocer o tomar conciencia del mundo para luego transformarlo, sino conocer el mundo desde y en la práctica transformadora, en la cual intervienen deseos, valores, voluntades, emociones, imaginación, intenciones y utopías" (TORRES CARRILLO, 2014, p. 33). Se trata de un proceso inacabado, dado que el mundo y quienes lo habitamos estamos en constante cambio, en el cual al conocer y transformar nos vamos trans-formando también a nosotrxs mismxs, a nuestros saberes y a nuestras preguntas (TORRES CARRILLO, 2014). 
A su vez, este momento fue el que mayores contradicciones trajo entre el decir y el hacer y, quizá por eso, podríamos considerarlo como el momento de mayor potencialidad para el aprendizaje, saliéndose, como ya explicitamos, del discurso de lo políticamente correcto. En este sentido, por ejemplo, en el Taller 2019 al intervenir 'con buenas intenciones' para transformar la realidad opresiva hacia Gerónima y su familia, se fueron sucediendo en cascada diferentes propuestas de modificación, pero que prácticamente no estuvieron dirigidas al personaje de Gerónima, lo cual se ponía en tensión al habilitar la voz y los sentimientos de quien encarnaba ese personaje. Esto incluyó a aquello que caracterizamos como 'solución mágica', pero también al resto de las propuestas que le daban agencia, capacidad de transformarse al resto de los personajes. Aun habiendo personas que participaban en organizaciones sociales con intencionalidades emancipatorias, se encontraron en contradicción, al no coincidir sus acciones con sus propósitos de transformación social. Una de las participantes, de gran compromiso militante en su vida, rememoró este momento del Taller como fundamental y como el que más la interpeló, haciéndola reflexionar sobre su propia práctica.

Otro aspecto interesante del momento de la transformación de la imagen fue la necesidad de Ixs propixs protagonistas de participar en las modificaciones, si bien esto no estaba incluido en el esquema de la planificación original. En el caso del Taller 2018 A, el grupo de mujeres que actuaban modificaron la posición en la que las habían colocado, quedando el hombre que representaba al patriarcado tirado en el piso y el grupo de mujeres alrededor de él con los puños en alto. En el Taller 2018 B, quien representaba a Gerónima, pidió transformar la situación, sacándose y pateando unas zapatillas que tenía mal puestas, para liberarse de la imposición de utilizar un tipo de calzado que no era cómodo para ella. En el caso del Taller 2019, fue el gendarme quien preguntó si podía realizar modificaciones a la imagen y cambió el vínculo entre la médica y la hija de Gerónima, haciendo que se tomaran de la mano y se miraran a los ojos.

Resaltamos la posibilidad de abrir la dimensión transformadora, aunque entendemos desde nuestra propia experiencia que suele ser de las más esquivas para abordar, especialmente en talleres de corta duración. Como indicó una de las entrevistadas: "siempre como que nos quedamos medio cortos, y como que uno, sigue haciendo diagnóstico, sigue haciendo diagnóstico y realmente, cómo se hace para que realmente las personas piensen que hay posibilidades de otra cosa, ¿no?". Como indica Boal (2001), el TO en sí mismo, en todas sus formas, es una apuesta a la acción, a la preparación para las acciones futuras, a la transformación de la realidad en un sentido de liberación de las opresiones. Incluso más, como indica Boal, en este vínculo entre transformación y aprendizaje, podemos entender que el "[...] teatro es una forma de conocimiento", y es a la vez "[...] un medio de transformar la sociedad" (BOAL, 2001, p. 23).

Muchxs de Ixs entrevistadxs hicieron referencia a diversas interpelaciones a sus prácticas a partir del Taller, sea por las ideas vinculadas a la salud o a la interculturalidad o respecto de la educación en general. Sin embargo, a pesar de valorar la propuesta, ningunx llevó el teatro a sus prácticas educativas por sentir que les faltaba formación para poder coordinarlo. Un caso destacable fue el de las promotoras de salud participantes en el Taller 2019, quienes dijeron haberse ido muy 
movilizadas, con muchas ideas y propuestas para transformar su propia práctica y para poner a consideración de su organización. Particularmente, a partir de lo vivenciado, describieron la intencionalidad de transformar su manera de vincularse y dialogar con su comunidad, buscando evaluar en conjunto las problemáticas de salud presentes en su territorio.

\section{Releyendo la sistematización: el taller como experiencia}

Como momento final de la sistematización, luego de todo el proceso colectivo de reflexión sobre la práctica que significó, vinculamos teóricamente la propuesta analizada con la categoría de experiencia (JARA H., 2018). Según Jara H. (2018, p. 61),

[en el] entramado complejo, multidimensional y pluridireccional de factores objetivos y subjetivos que constituye lo que llamamos experiencia, no hay simplemente hechos y cosas que suceden; hay personas que hacemos que ellos ocurran y que nos impacten: personas que pensamos, sentimos, vivimos, hacemos que esos hechos se den en contextos y situaciones determinadas y que al hacerlo se convierten en nuevas experiencias que construyen, a su vez, nuevos contextos, situaciones, emociones y relaciones, en una dinámica histórica de vinculaciones y movimientos que nunca concluye.

Entendemos que las características de la propuesta desarrollada tuvieron la intencionalidad de poner en juego y desplegar estas múltiples dimensiones y direcciones de lo experiencial. Incluir explícitamente el cuerpo, los sentimientos, el diálogo, la transformación, la reflexión teórica, la mirada crítica en un contexto de Taller, como en el caso aquí descrito, puede ser uno de los caminos para planificar procesos educativos buscando abarcar la complejidad de la experiencia.

Siguiendo con la mirada de Jara H. (2018), las personas vivimos las experiencias con todo nuestro recorrido y con todo nuestro ser, con nuestros saberes, dudas, expectativas, sueños, temores, esperanzas, ilusiones, ideas e intuiciones y es en esas mismas experiencias con otrxs que nos vamos transformando. Somos quienes

[...] hacemos que ocurran esos procesos complejos y dinámicos, y esos procesos, a su vez, nos marcan, nos impactan, nos condicionan, nos exigen, nos hacen ser. Las experiencias son individuales y colectivas a la vez, las vivimos y nos hacen vivir." (JARA H., 2018, p. 62).

Así, la idea de experiencia puede erigirse como una forma de entender los procesos educativos en todo su entramado complejo, dialéctico, de seres humanos que se encuentran desde sus vivires con todas sus aristas. Entender la educación, y especialmente la ES, de esta manera, desbordando multidimensionalmente las concepciones hegemónicas, permite no mutilarla, nutrirla, hacerla más rica.

\section{A modo de cierre}

A lo largo de este trabajo presentamos, a modo de entramados y de capas superpuestas, la sistematización que hicimos de nuestra propia práctica en talleres de formación que articularon la Salud, la Interculturalidad y el Teatro del Oprimido. Primero describimos la estructura de los talleres y su contexto, luego confeccionamos escenas que retomaban la experiencia vivida y que intentaron ser un medio locuaz para comunicarla. Finalmente, reflexionamos sobre la práctica, encontrando aprendizajes 
interconectados con referenciales teóricos desde donde vinculamos con el $\mathrm{MMH}$, la Epidemiología Crítica, la interculturalidad crítica y extendida, el diálogo de vivires, la sociología de la imagen y la EP. A su vez, la sistematización realizada nos permitió reconocer, entre muchos otros aspectos, que el uso del Teatro Imagen como dispositivo didáctico implicó un proceso de aprendizaje desarrollado en la propia práctica. Tal proceso, al menos en este caso, parece haber posibilitado poner en juego múltiples posturas, incluyendo las políticamente incorrectas. Destacamos también la riqueza para el aprendizaje del uso de dispositivos que habiliten la dimensión de la transformación de la realidad en temáticas como Salud e Interculturalidad. Y, finalmente, reconocimos, a partir de nuestra sistematización, la multidimensionalidad y pluridireccionalidad de la experiencia vivida y analizada.

Consideramos que el trabajo realizado contribuye tanto al campo de la investigación educativa, cuanto al de las prácticas de formación en ES. Por un lado, la comprensión densa y las diversas propuestas para potenciar la experiencia formativa logradas a través de la sistematización reafirman su valor como metodología de investigación cualitativo-crítica para el campo de la ES. Por el otro, el propio Taller descrito, fundamentado y analizado puede constituirse en una inspiración para otrxs formadorxs, docentes y colectivos que deseen construir una ES desde una perspectiva integral, democrática, participativa y emancipadora. En este contexto de crisis planetaria y de pandemia, aportar a una ES con estas características no sólo resulta necesario, sino además urgente.

\section{Referencias}

BOAL, A. Juego para actores y no actores. Barcelona: Alba, 2001.

BREILH, J. La determinación social de la salud como herramienta de ruptura hacia la nueva salud pública (salud colectiva). Epidemiología crítica latinoamericana: raíces, desarrollos recientes y ruptura metodológica. Revista de la Facultad Nacional de Salud Pública, Medellín, n. 31, sup. 1, p. 13-27, 2013.

CORDERO, S.; DUMRAUF, A.; MENGASCINI, A.; SANMARTINO, M. Entre la didáctica de las ciencias naturales y la educación popular en ciencias naturales, ambiente y salud: relatos y reflexiones de un camino en construcción. Praxis Educativa, Santa Rosa, v. 15, n. 15, p.71-79, 2011.

CORDERO, S.; GARELLI, F.; CUCALÓN, P. Poniéndole el cuerpo a la educación en salud y la interculturalidad en el desarrollo profesional docente. In: JORNADAS DE ENSEÑANZA E INVESTIGACIÓN EDUCATIVA EN EL CAMPO DE LAS CIENCIAS EXACTAS Y NATURALES, 5., 2019, Ensenada. Actas [...]. Ensenada: Universidad Nacional de La Plata, 2019. p. 1-12. Recuperado el 19 ago. 2021 de: https://cutt.ly/IQ0FxJm.

CORDERO, S.; MENGASCINI, A.; MENEGAZ, A.; ZUCCHI, M.; DUMRAUF, A. La alimentación desde una perspectiva multidimensional en la formación de docentes en ejercicio. Ciência \& Educação, Bauru, v. 22, n. 1, p. 219-236, 2016. DOI: https://doi.org/grsz.

CUCALÓN, P.; CORDERO, S.; DUMRAUF, A. G. Interculturalidad y educación en ciencias naturales, ambiente y salud en la provincia de Buenos Aires. In: REUNIÓN DE ANTROPOLOGÍA DEL MERCOSUR, 12., 2017, Posadas. Actas [...]. Posadas, Argentina, 2017.

DÍAZ, R.; RODRÍGUEZ DE ANCA, A. Activismo intercultural: una mirada descolonizadora, crítica e interseccional. In: VILLA, A. I.; MARTÍNEZ, M. E. (comp.). Relaciones escolares y diferencias culturales: la educación en perspectiva intercultural. Buenos Aires: Noveduc, 2014. p. 171-198. 
DIEZ, M. L. Repensando la interculturalidad en educación: aportes de la investigación socioantropológica a un campo problemático. Revista Docencia, Santiago, Chile, v. 51, p. 5-17, 2013.

DUMRAUF, A. G.; CORDERO, S.; CUCALÓN, P.; GUERRERO TAMAYO, K.; GARELLI, F. Hacia nuevos territorios epistémicos: aportes desde un camino de construcción pedagógica descolonizadora en educación en ciencias naturales, ambiental y en salud. In: MONTEIRO, B. et al. (ed.).

Decolonialidades na educação em ciências. São Paulo: Livraria da Física, 2019. p. 288-306.

DUMRAUF, A. G.; CORDERO, S.; MENGASCINI, A. S. Experiencias educativas de los movimientos sociales: contribuciones para la educación científica, ambiental y en salud desde una perspectiva emancipadora. Revista Brasileira de Pesquisa em Educação em Ciências, Belo Horizonte, v. 16, p. 477-497, 2016.

DUMRAUF, A. G.; GARELLI, F. M. Biomedicina-tecnología-sociedad y COVID-19: miradas críticas, esperanzas y educación en salud. Boletim de la AIA-CTS, Aveiro, n. 13, p. 21-28, 2020.

FAINSOD, P.; BUSCA, M. Educación para la salud y género: escenas del curriculum en acción. Rosario: Homo Sapiens, 2016.

GARELLI, F.; MENGASCINI, A.; CORDERO, S.; DUMRAUF, A. Formación docente y representaciones sobre salud: caminos para la educación en salud desde una mirada crítica. Ensaio, Belo Horizonte, v. 19, e2558, p. 1-20, 2017. DOI: https://doi.org/grs2.

GERÓNIMA. Dirección: Raúl Alberto Tosso. Producción de Luís Martín Barberis. [S. I.]: Cooperativa de Producción del Instituto de Arte Cinematográfico, 1986.

JARA H., O. La sistematización de experiencias: práctica y teoría para otros mundos políticos. Bogotá: Centro Internacional de Educación y Desarrollo Humano, 2018.

MACHADO ARÁOZ, H. La pandemia como síntoma del capitaloceno: la arrogancia de la razón. La Tinta: periodismo hasta mancharse, 16 abr. 2020. Recuperado el 10 sep. 2020 de: https://cutt. $\mathrm{ly} / 7 \mathrm{QOHCHh}$.

MENÉNDEZ, E. L. El modelo médico y la salud de los trabajadores. Salud Colectiva, Lanús, v. 1, n. 1, p. 9-32, 2005. DOI: https://doi.org/10.18294/sc.2005.1.

MERÇON, J.; CAMOU-GUERRERO, A.; NÚÑEZ MADRAZO, C.; ESCALONA AGUILAR, M. A. ¿Diálogo de saberes?: la investigación acción participativa va más allá de lo que sabemos. Decisio, México, n. 38, p. 29-33, 2014.

PARO, C. A.; SILVA, N. E. K. Teatro do oprimido e promoção da saúde: tecendo diálogos. Trabalho, Educação, Saúde, Rio de Janeiro, v. 16, n. 2, p. 471-493, 2018. DOI: https://doi.org/grs3.

PALUMBO, M. M. Operatorias epistémicas em talleres de formación política de movimientos populares en Argentina. Entre Diversidades, San Cristóbal de Las Casas, Mexico, v. 7, n. 1, p. 276305, 2020. DOI: https://doi.org/grs5.

RÉDUA, L. S.; KATO, D. S. Oficinas pedagógicas na formação inicial de professores de ciências e biologia: espaço para formação intercultural. Ciência \& Educação, Bauru, v. 26, e20001, 2020. DOI: https://doi.org/grs6.

RIVERA CUSICANQUI, S. Ch'ixinakax Utxiwa: una reflexión sobre prácticas y discursos descolonizadores. Buenos Aires: Tinta Limón, 2014.

TORRES CARRILLO, A. Educación popular y movimientos sociales en América Latina. Buenos Aires: Biblos, 2014. 